\title{
Fuzzy PID Controllers Using FPGA Technique for Real Time DC Motor Speed Control
}

\author{
Basil Hamed, Moayed Almobaied \\ Electrical Engineering Department, Islamic University of Gaza, Gaza, Palestine \\ E-mail: bhamed@iugaza.edu \\ Received April 3,2011; revised June 10, 2011; accepted June 17, 2011
}

\begin{abstract}
The design of intelligent control systems has become an area of intense research interest. The development of an effective methodology for the design of such control systems undoubtedly requires the synthesis of many concepts from artificial intelligence. The most commonly used controller in the industry field is the proportional-plus-integral-plus-derivative (PID) controller. Fuzzy logic controller (FLC) provides an alternative to PID controller, especially when the available system models are inexact or unavailable. Also rapid advances in digital technologies have given designers the option of implementing controllers using Field Programmable Gate Array (FPGA) which depends on parallel programming. This method has many advantages over classical microprocessors. In this research, A model of the fuzzy PID control system is implemented in real time with a Xilinx FPGA (Spartan-3A, Xilinx Company, 2007). It is introduced to maintain a constant speed to when the load varies. The model of a DC motor is considered as a second order system with load variation as an example for complex model systems. For comparison purpose, two widely used controllers "PID and Fuzzy" have been implemented in the same FPGA card to examine the performance of the proposed system. These controllers have been tested using Matlab/Simulink program under speed and load variation conditions. The controllers were implemented to run the motor as real time application under speed and load variation conditions and showed the superiority of Fuzzy-PID.
\end{abstract}

Keywords: DC Motor, Fuzzy Logic Control, PID Controller, Real Time, FPGA

\section{Introduction}

Due to its excellent speed control characteristics DC motor has been widely used in industry even though its maintenance costs are higher than the induction motor, the speed of DC motor can be adjusted to a great extent so as to provide easy control and high performance [1,2]. At present, Proportional-Integral-Derivative "PID" controller, due to its simplicity, stability, and robustness, is a type of controller that is most widely applied $[2,3]$. However, it is difficult to design when the accurate model of plant is complicated or the environment of the load on the plant is variable. For Dc motors, factors such as unknown load characteristic and parameter variation influence seriously the controlling effect of speed controller. Fuzzy control does not strictly need any mathematical model of the plant. It is based on plant operator experience, and it is very easy to apply. Fuzzy Logic has been successfully applied to a large number of control applications. The most commonly used controller is the proportional-plus-integral-plus-derivative controller, which requires a mathematical model of the system. Fuzzy logic controller provides an alternative to PID controller since it is a good tool for the control of systems that are difficult in modeling. The control action in fuzzy logic controllers can be expressed with simple "if-then" rules. Fuzzy control gives robust performance for a linear or nonlinear plant with parameter variation. Hardware implementation of the controller can be achieved in a number of ways to create new products [4]. The most popular method of implementing Fuzzy controller is using a general-purpose microprocessor or microcontroller. The simple and usual way to implement these systems is to realize it as a software program on general purpose computers, these ways cannot be considered as a suitable design solution [5]. Higher density programmable logic device such as Field Programmable Gate Arrays (FPGAs) can be used to integrate large amounts of logic in a single 
IC. FPGAs are one of the fastest growing parts of the digital integrated circuit market in recent times [6]. Rapid advances in digital technologies have given designers the option of implementing a controller on a variety of Programmable Logic Device (PLD), Field Programmable Gate Array (FPGA), etc. [6]. FPGA is suitable for fast implementation controller and can be programmed to do any type of digital functions. Applications of FPGAs include industrial motor drivers, real time systems, digital signal processing, computer hardware emulation and a growing range of other areas. The novel approach, which is proposed in this research, is: Design and practical implementation of a real time Fuzzy-PID controller using modern FPGA card (Spartan-3A, Xilinx Company, 2007) for speed control of DC motor with load variation as an application. This paper is organized into six sections. Section 2 handles basic principles of our DC motor. Section 3 focuses on Fuzzy logic sets. Section 4 deals with FPGA and VHDL software implementation. Section 5 presents the design of the three types of controllers; also, the simulation and results are included. The last section concludes the design and the implementation of the system.

\section{DC Motor}

DC motor shown in Figure 1 is the one of most common motors which used in industrial motion control systems.

Figure 2 display the electric circuit of the armature and the free body diagram of the rotor in DC motor. Table 1 contains the motor parameters used in this paper.
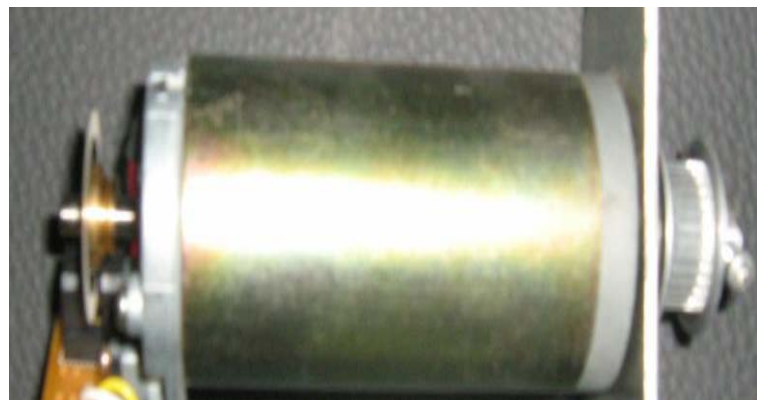

Figure 1. DC motor.

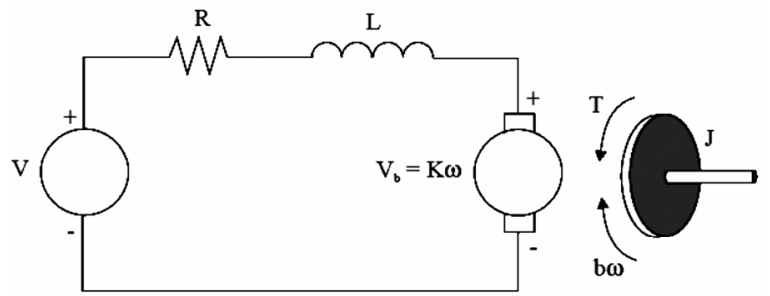

Figure 2. Schematic representation of the considered DC motor.
Table 1. Dc motor parameters.

\begin{tabular}{ll}
\hline Parameter & Value \\
\hline $\begin{array}{ll}\text { Moment of inertia of the rotor } \\
\begin{array}{l}\text { Damping (friction) of the mechanical } \\
\text { system }\end{array}\end{array}$ & $J=0.00025 \mathrm{Nm} / \mathrm{rad} / \mathrm{s}^{2}$ \\
$\begin{array}{l}\text { Terminal resistance } \\
\text { Terminal inductance }\end{array}$ & $R A=0.0001 \mathrm{Nm} / \mathrm{rad} / \mathrm{s}$ \\
Electromotive force constant & $K=0.05 \mathrm{Nm} / \mathrm{A}$ \\
\hline
\end{tabular}

The input is the armature voltage $V$ in Volts, and the measured variables are the angular velocity of the shaft $w$ in radians per second. The motor torque, $T$, is related to the armature current, $i$, by a constant factor $K$ :

$$
T=K i
$$

The back electromotive force (emf) $V b$, is related to the angular velocity by:

$$
V_{b}=\mathrm{K} \omega=\mathrm{K} \frac{\mathrm{d} \theta}{\mathrm{d} t}
$$

From Figure 2 we can write the following equations based on the Newton's law combined with the Kirchhoff's law:

$$
\begin{aligned}
& J \frac{\mathrm{d}^{2} \theta}{\mathrm{d} t^{2}}+b \frac{\mathrm{d} \theta}{\mathrm{d} t}=K i \\
& L \frac{\mathrm{d} i}{\mathrm{~d} t}+R i=V-K \frac{\mathrm{d} \theta}{\mathrm{d} t}
\end{aligned}
$$

Using the Laplace transform, equations (3) and (4) can be written as:

$$
\begin{gathered}
J s^{2} \theta(s)+b s \theta(s)=K I(s) \\
L s I(s)+R I(s)=V(s)-K s \theta(s)
\end{gathered}
$$

From (6) we can express $I(s)$ :

$$
I(s)=\frac{V(s)-K s \theta(s)}{R+L s}
$$

And substitute it in (5) to obtain:

$$
J S^{2} \theta(s)+b s \theta(s)=K \frac{V(s)-K s \theta(s)}{R+L s}
$$

This equation for the DC motor is shown in the block diagram at Figure 3.

From the block diagram in Figure 3, it is easy to see that the transfer function from the input voltage, $V(s)$, to the angular velocity.

$$
G_{a}(s)=\frac{\theta(s)}{V(s)}=\frac{K}{s\left[(R+L s)(J s+b)+K^{2}\right]}
$$




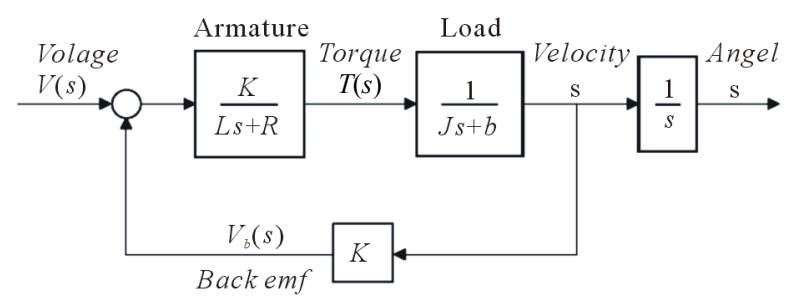

Figure 3. A block diagram of the DC motor.

$$
G_{v}(s)=\frac{\omega(s)}{V(s)}=\frac{K}{(R+L s)(J s+b)+K^{2}}
$$

\section{Fuzzy Logic}

Fuzzy Logic (FL) is an approach to control engineering problems, which mimics how a person would make decisions, only much faster. FL incorporates a simple rule-based " IF X AND Y THEN Z "approach to a solving control problem rather than attempting to model a system mathematically $[7,8]$. The FL model is empirically-based, relying on an operator's experience rather than his technical understanding of the system. In other words fuzzy logic is used in system control and analysis design, because it shortens the time for engineering development and sometimes, in the case of highly complex systems, is the only way to solve the problem $[9,10]$. Every Fuzzy system is composed of four principal blocks as shown in Figure 4:

1) Knowledge base: Rules and parameters for membership functions.

2) Decision making unit: Inference operations on the rules.

3) Fuzzification interface: Transformation of the crisp inputs into degrees of match with linguistic variables.

4) Defuzzification interface: Transformation of the Fuzzy result of the inference into a crisp output.

\section{Field Programmable Gate Arrays (FPGAs)}

FPGAs shown in Figure 5, stands for Field Programmable Gate Arrays are one type of programmable logic devices (PLDs). It is based on an integrated circuit that can be configured by the user in order to implement digital logic functions of varying complexities. FPGAs can be very effectively used for control purposes in processes demanding very high loop cycle time. One of the fundamental advantage of FPGA over DSP or other microprocessors is the freedom of programming parallelism $[11,12]$. Since different parts of FPGA can be configured to perform independent functions simultaneously, its performance is just not tied to clock rate as in DSPs. This

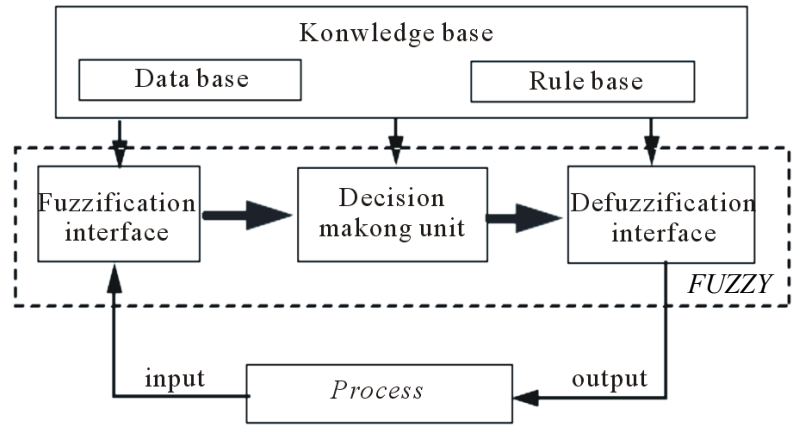

Figure 4. General structure of fuzzy inference system.

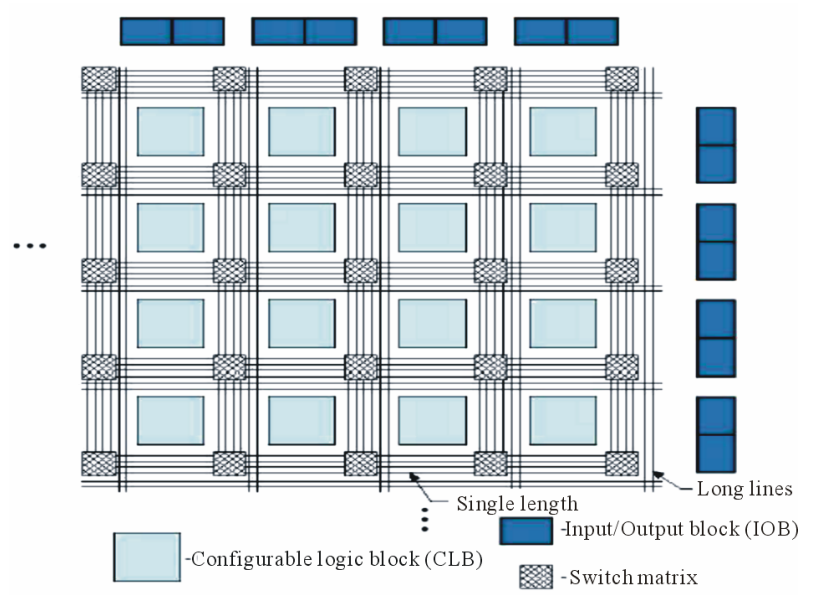

Figure 5. Structure of a Xilinx FPGA standard.

fact enables FPGA's to score over general purpose computing chips in the digital control systems implementation [13].

\section{Controllers Design}

This paper presents the process used to design three kinds of widely used controllers (PID, Fuzzy, and Fuzzy-PID) for the DC motor using FPGA technique. Figure 6 contains the main block diagram for the system.

To provide DC motor with the required voltage, we need a PWM driver shown in Figure 7. PWM is a way of digitally encoding analog signal levels. The duty cycle of a square wave is modulated to encode a specific analog signal level. The PWM signal is still digital

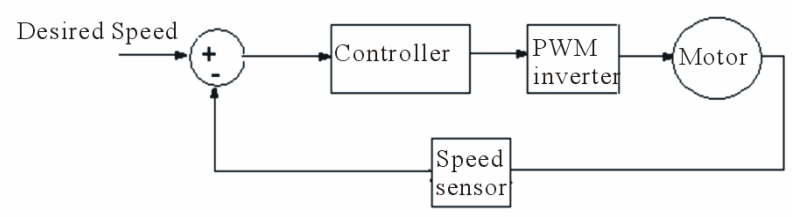

Figure 6. Block diagram for DC motor controller. 


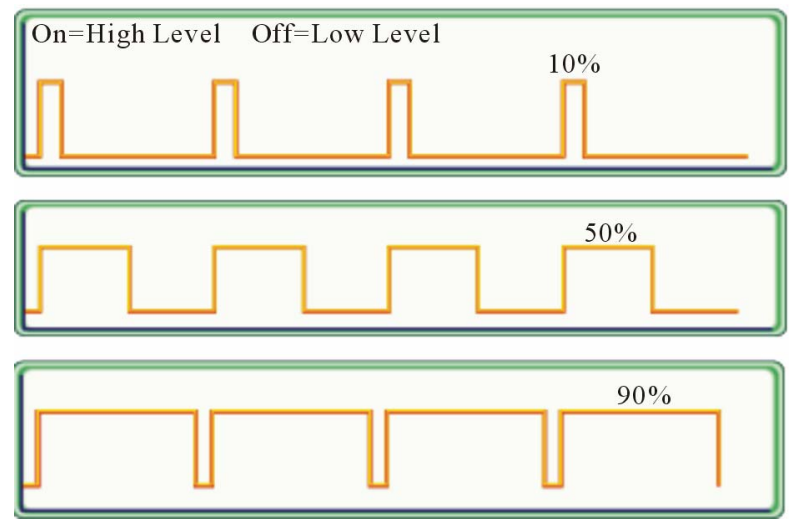

Figure 7. PWM signals.

because, at any given instant of time, the full DC supply is either fully on or fully off. The voltage or current source is supplied to the analog load by means of a repeating series of on and off pulses. Figure 7 shows three different PWM signals with PWM output at a $10 \%$, $50 \%$, and $90 \%$ duty cycles, respectively. These three PWM outputs encode three different analog signal values, at $10 \%, 50 \%$, and $90 \%$ of the full strength of the Dc voltage [13].

Three different controllers were developed in this paper: PID controller, Fuzzy controller, and Fuzzy-PID controller. Finally, a comparison will be made among these controllers to find the best performer.

\subsection{PID Controller}

The block diagram of a PID controller algorithm is shown in Figure 8.

It's required to build a digital PID controller in the FPGA card. There are many approaches are available to convert from analogue to digital. In this proper we used the Tus- tin approach. The equation which represents the PID controller is:

$$
u(t)=K_{p} e(t)+K_{i} \int e(t) \mathrm{d} t+K_{d} \frac{\mathrm{d} e(t)}{\mathrm{d} t}
$$

There are many methods available to get the best values of $\mathrm{K}_{\mathrm{p}}, \mathrm{K}_{\mathrm{i}}$, and $\mathrm{K}_{\mathrm{d}}$. One approach is to use a technique that was developed in the 1950's but has stood the time and is still used today. This is known as the Ziegler Nichols tuning method [14].

A general rule of thumb in control design is to sample at least 4 to 20 times the rise time of the system response, so the sampling time will be chosen to 4.1 milliseconds. Hence, the output of the PID controller will feed to the plant speed register of the PWM.

The Simulink block diagram for the PID speed controller for DC motor is shown in Figure 9. The controller has been tested using Simulink in Matlab. The result of
PID controller is shown in Figure 10.

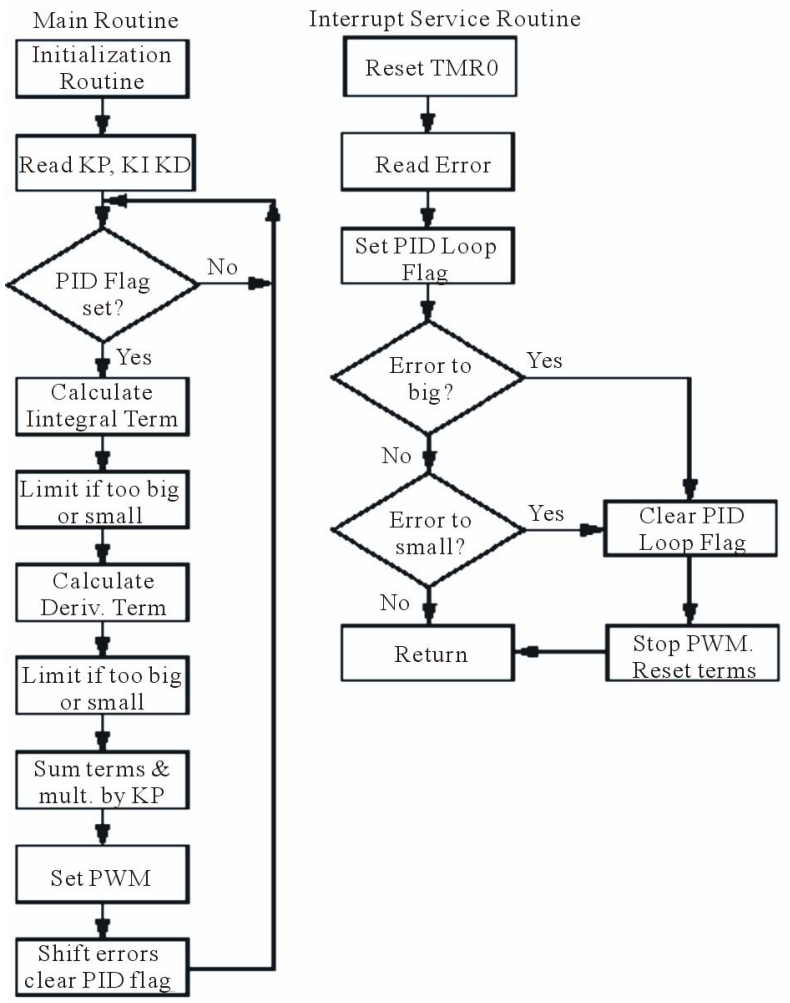

Figure 8. PID algorithm.

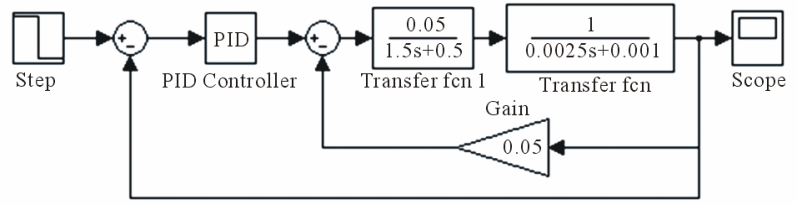

Figure 9. PID speed controller for Dc motor.

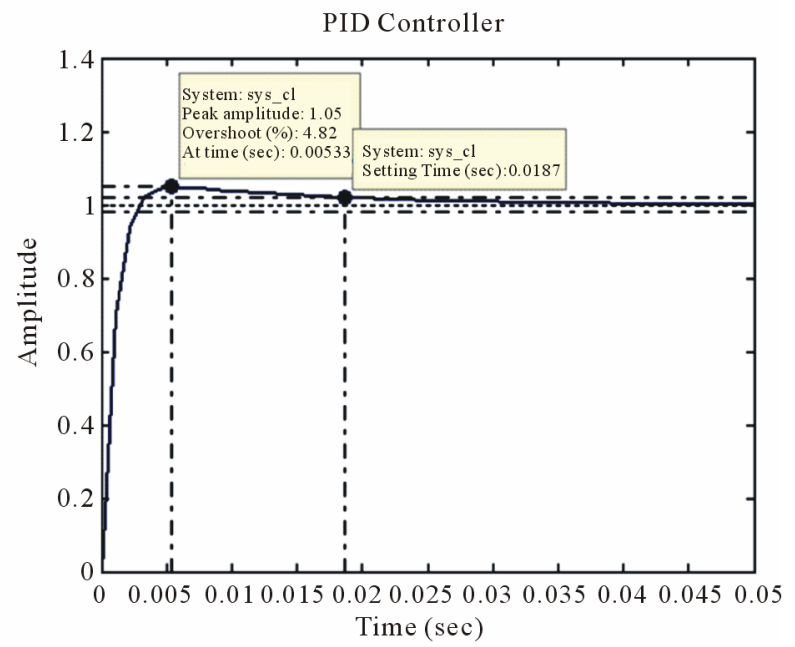

Figure 10. PID controller step response. 


\subsection{Fuzzy Logic Controller "FLC"}

FLC has been constructed Using VHDL and embedded PicoBalze processor in FPGA. The block diagram for the FLC for the DC motor is shown in Figure 11.

FLC has two inputs, which are: Error (E) and the Error change (CE), and one output feeding to the plant speed register of the PWM. Figure 12 illustrates the method used in reaching the desired speed value. For example, at stage A the Error is positive (desired speed -actual speed) and the Change Error (Error - last Error) is negative, which mean that the response is heading in the right direction; hence, the FLC will go forward in this direction. Using the same criteria at stage B, the Error is negative and $\mathrm{CE}$ is big negative; hence, the response is heading in wrong direction so FLC will change its direction to enter Stage C, until reaching the desired speed.

In this paper, Mamdani approach in FPGA has been used to implement FLC for the DC motor. FLC contains three basic parts: Fuzzification, Base rule, and Defuzzification.

\subsubsection{Fuzzification}

The Fuzzy set of the Error input which contains 7 Triangular memberships is shown in Figure 13.

Figure 14 illustrates the Fuzzy set of the Change Error input which contains 7 Triangular memberships.

Figure 15 illustrates the Fuzzy set of the output which contains 7 Triangular memberships.

\subsubsection{Control Base Rules}

Table 2 presents the knowledge base defining the rules for the desired relationship between the input and output

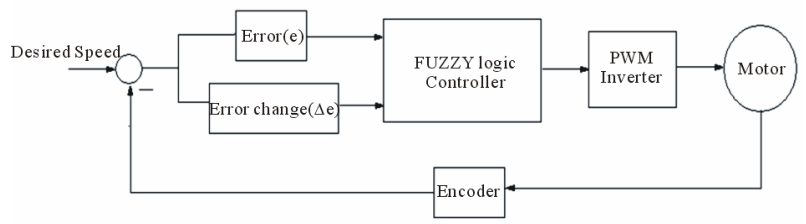

Figure 11. FLC speed controller for Dc motor.

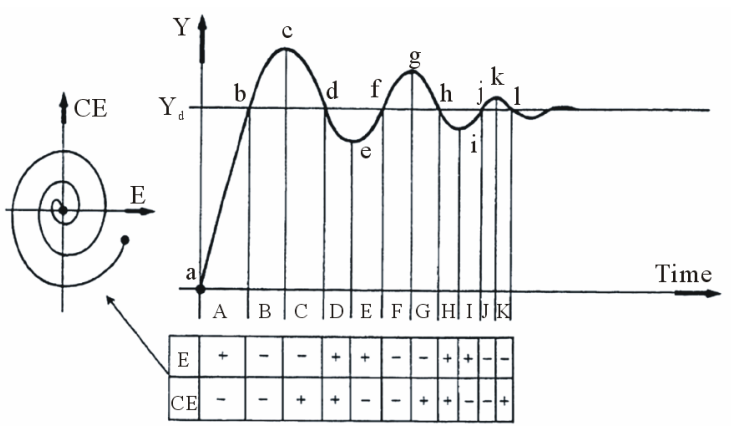

Figure 12. Error and error change approach in FLC.

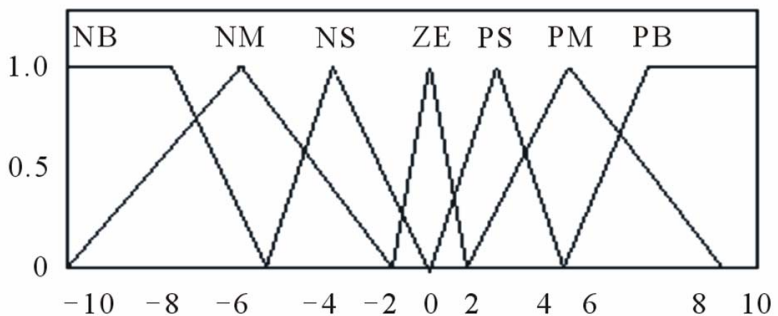

Figure 13. Error fuzzy set of FLC.

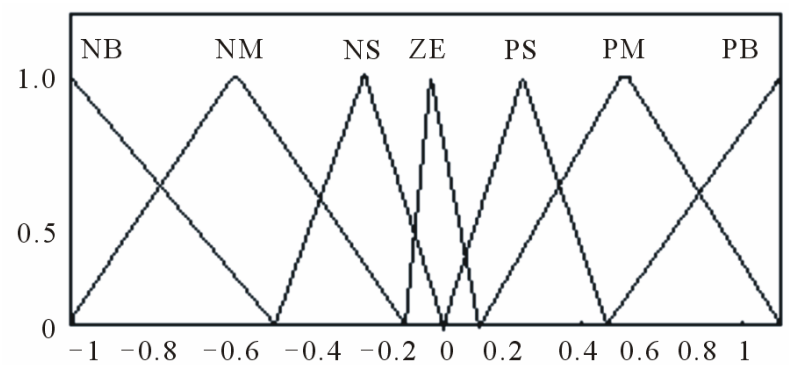

Figure 14. Change error fuzzy set of FLC.

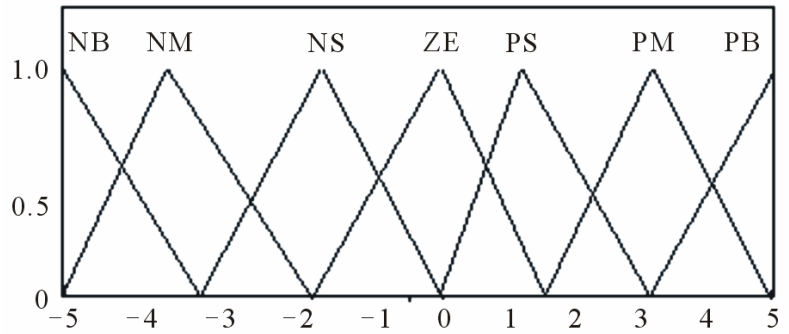

Figure 15. Fuzzy set of FLC output entering to plant speed register.

Table 2. Fuzzy controller base rules

\begin{tabular}{llllllll}
\hline CE & NB & NM & NS & ZE & PS & PM & PB \\
\hline NB & NB & NB & NB & NB & NM & NS & ZE \\
NM & NB & NB & NM & NM & NS & ZE & PS \\
NZ & NB & NM & NS & NS & ZE & PS & PM \\
ZE & NB & NM & NS & ZE & PS & PM & PB \\
PS & NM & NS & ZE & PS & PS & PM & PB \\
PM & NS & ZE & PS & PM & PM & PB & PB \\
PB & ZE & PS & PM & PB & PB & PB & PB \\
\hline
\end{tabular}

variables in terms of the membership functions. The control rules are represented as a set of:

IF Error is.. and Change Error is $\cdots$ THEN the output will $\cdots$.

Figure 16 shows the surface of the base rules used in FLC. 


\subsubsection{Defuzzification}

The center of gravity "centroid" method was used in this paper. Figure 17 shows the Simulink block diagram for the Fuzzy speed controller for DC motor. The controller has been tested using Simulink in Matlab. The result of Fuzzy controller is shown in Figure 18.

\subsection{Fuzzy-PID Controller}

Here, another approach which depends on mixing the PID controller with Fuzzy controller in FPGA using VHDL code. Hence, the value of the PID parameters will be evaluated using the Fuzzy controller. A complete design of the system is shown in Figure 19. The Fuzzy sets

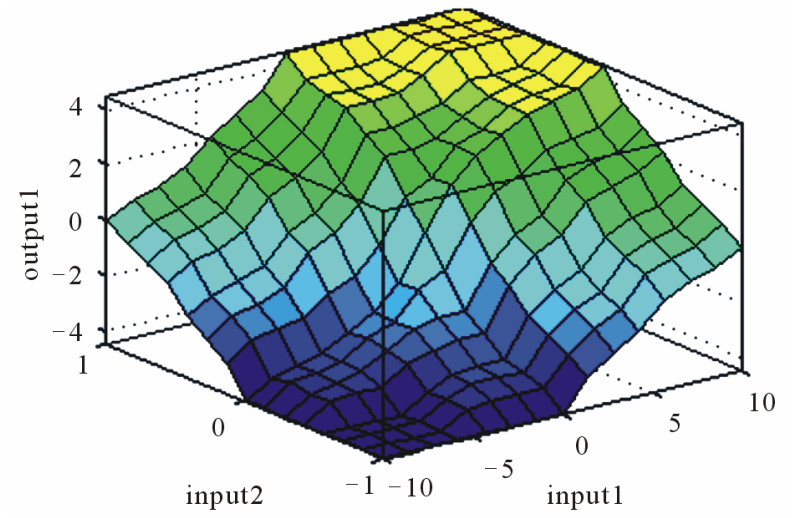

Figure 16. Rules surface of FLC

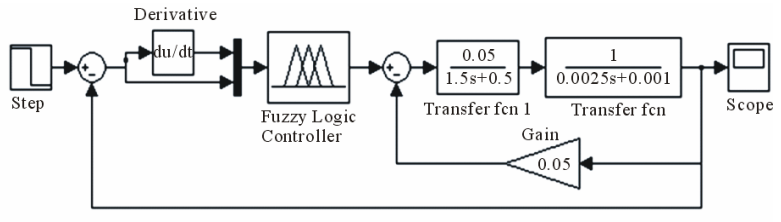

Figure 17. Fuzzy logic speed controller.

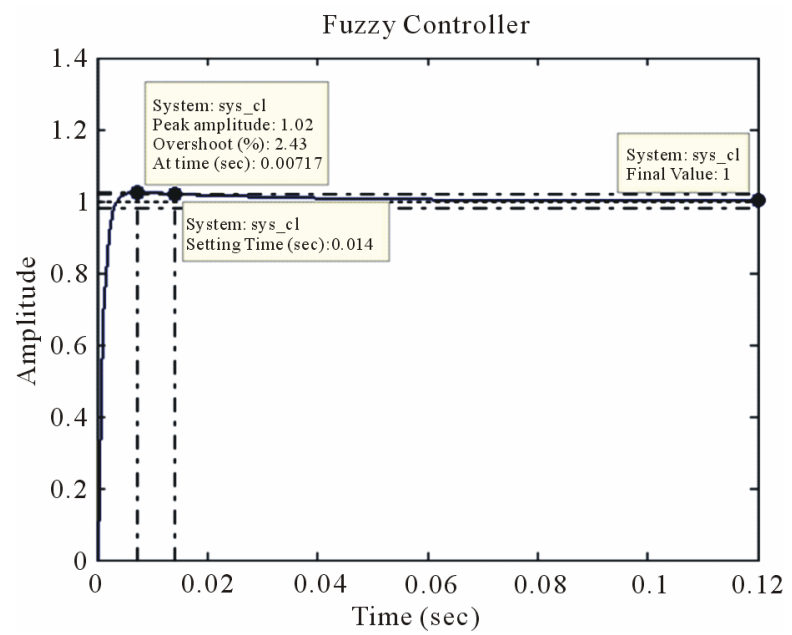

Figure 18. Fuzzy controller step response. for the output: $K_{p}, K_{i}$, and $K_{d}$ is shown in Figure 20, practically there are three different Fuzzy sets for these parameters. The inputs of the controller used are the error and change of error as presented in the previous section.

Table 3 presents the base rules of Fuzzy-PID controller $\left(K_{p}\right)$. Practically there are three base rules tables for $K_{p}, K_{i, \text { and }} K_{d}$

Simulink block diagram for the Fuzzy-PID speed controller for DC motor is shown in Figure 21.

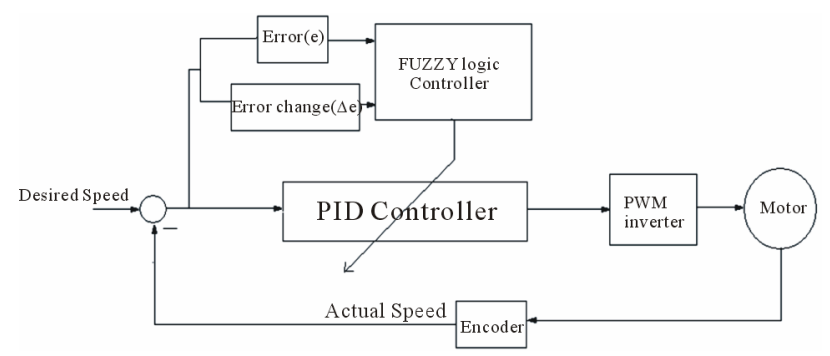

Figure 19. Fuzzy-PID controller for the induction motor.

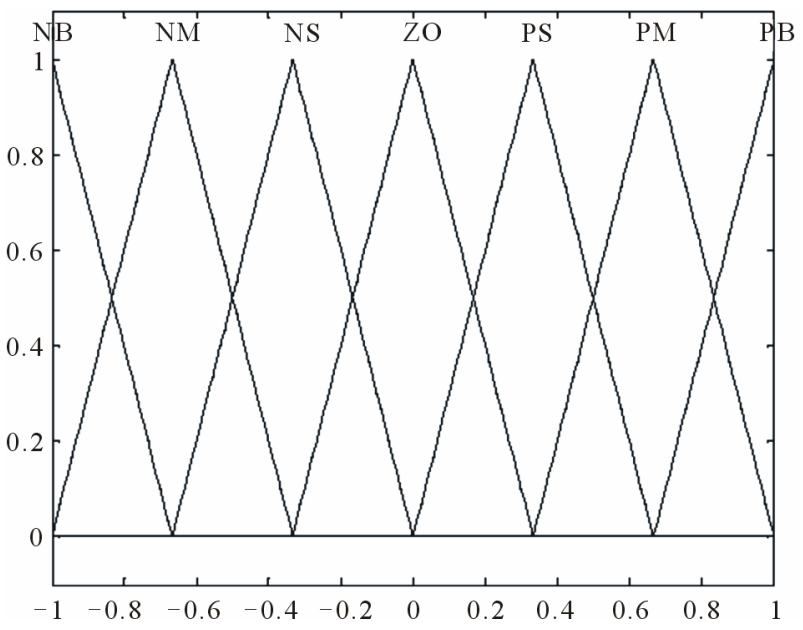

Figure 20. Fuzzy sets for $\mathrm{Kp}, \mathrm{Ki}$, and $\mathrm{Kd}$ with different memberships boundaries.

Table 3. Base rules for fuzzy-PID controller (Kp).

\begin{tabular}{cccccccc}
\hline CE & NB & NM & NS & ZE & PS & PM & PB \\
\hline PB & ZE & PS & PM & PB & PB & PB & PB \\
PM & NS & ZE & PS & PM & PB & PB & PB \\
PS & NM & NS & ZE & PS & PM & PB & PB \\
ZE & NB & NM & NS & ZE & PS & PM & PB \\
NS & NB & NB & NM & NS & ZE & PS & PM \\
NM & NB & NB & NB & NM & NS & ZE & PS \\
NB & NB & NB & NB & NB & NM & NS & ZE \\
\hline
\end{tabular}




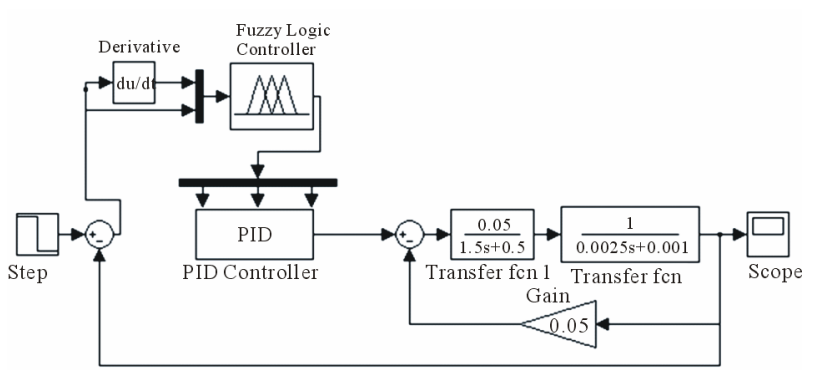

Figure 21. Fuzzy-PID logic speed controller.

The controller has been tested using Simulink in Matlab. The result of Fuzzy-PID controller is shown in Figure 22.

\subsection{Results Comparison}

Table 4 shows controller's comparison, hence it's found that the Fuzzy-PID controller is the best controller among the other controllers.

All three controllers presented in this paper are implemented in hardware using the FPGA card; then these controllers have been tested with real time experiments. An auxiliary program in the FPGA is implemented to test the step response of these controllers. Then our program displays the results on the LCD using the PicoBlaze processor technique as a real time tester. The LCD displays

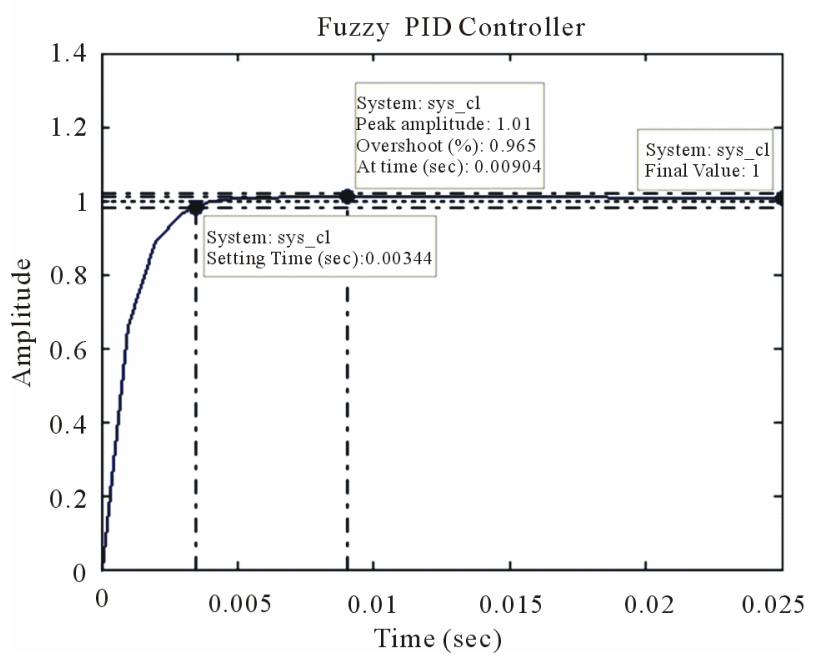

Figure 22. Fuzzy-PID controller step response.

Table 4. Controllers comparison.

\begin{tabular}{cccc}
\hline Controller & Overshoot & Settling time & Steady state error \\
\hline PID & 4.82 & 0.0187 & 0 \\
Fuzzy & 2.43 & 0.014 & 0 \\
Fuzzy-PID & 0.965 & 0.00344 & 0 \\
\hline
\end{tabular}

the desired speed, the overshoot, the settling time, and the PID parameters for each controller as shown in Figures 23 and 24. The result of the real time experiment we have is very close to the Matlab simulation. A digital optical encoder with two channels is used to read the speed of the motor, and it displays the direction of the motor as shown in Figure 25. Many features were applied to the system as overload protection, motor direction switch and also we used three switches to enter the controllers' type and to specify the parameters of the PID controller.

\subsection{Modelsim Results}

PWM algorithm was tested using Modelsim (VHDL simulator) program, which is a powerful simulator established by Xilinx Company. Using this simulator we can specify the input and the output ports then the simulator will test the VHDL code which shown in Figure 26.

\section{Conclusions}

In this paper, Fuzzy-PID controller has been selected to

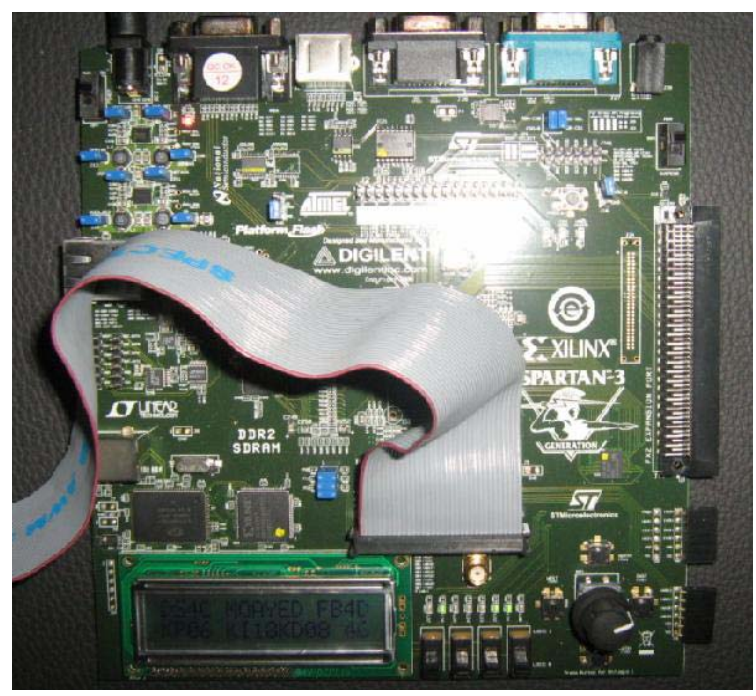

Figure 23. FPGA card with LCD and controlling keys.

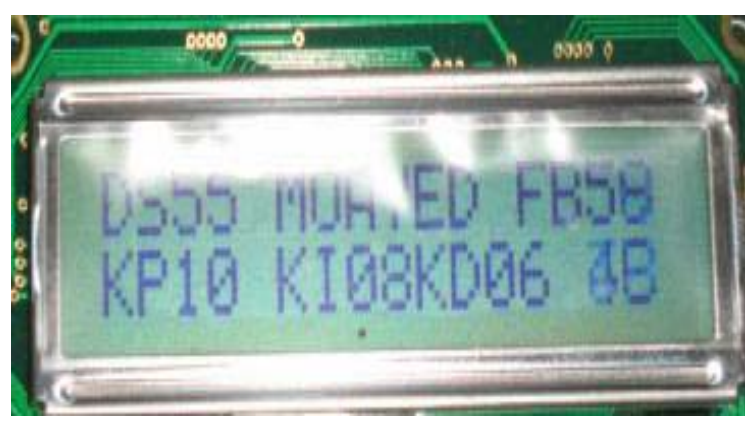

Figure 24. Real time experiments results on the LCD. 
control the speed of DC motor due to its advantages over the traditional PID controller. The control scheme was modeled and designed in VHDL. It was simulated and synthesized using the Xilinx Foundation package and implemented into a Xilinx Spartan 3-A FPGA (Figure 27). The experiments show that the dynamic response of a system using the proposed controller is better when compared to a classical PID, and Fuzzy controller. Also these controllers have been tested using Matlab/Simulink program under speed and load variation conditions. The comparison results showed that the Fuzzy-PID controller was the best controller.

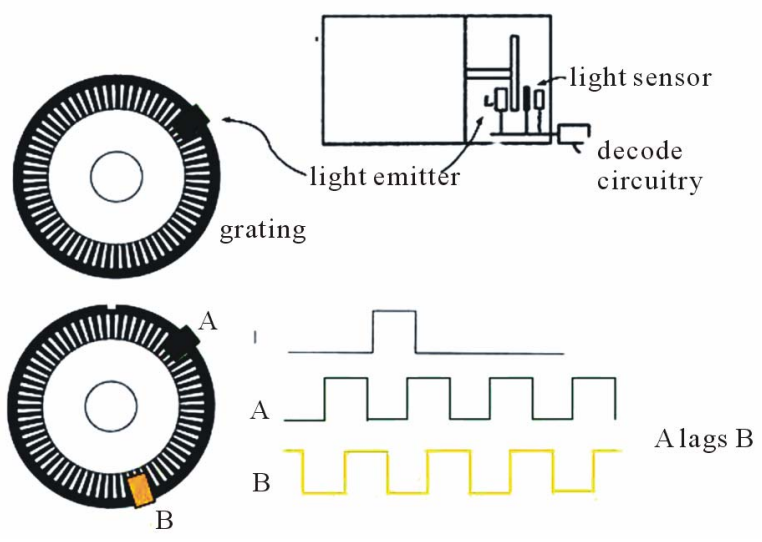

Figure 25. Digital optical encoder.

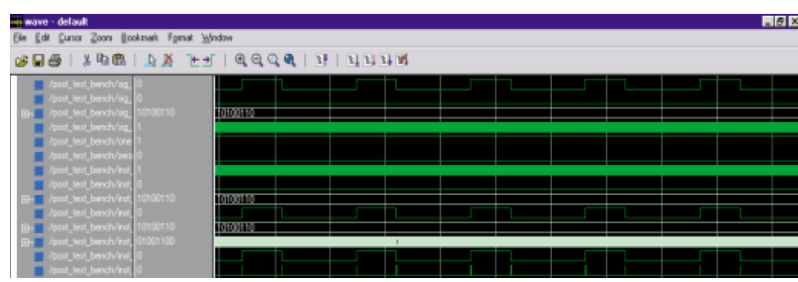

Figure 26. PWM modelsim signal.

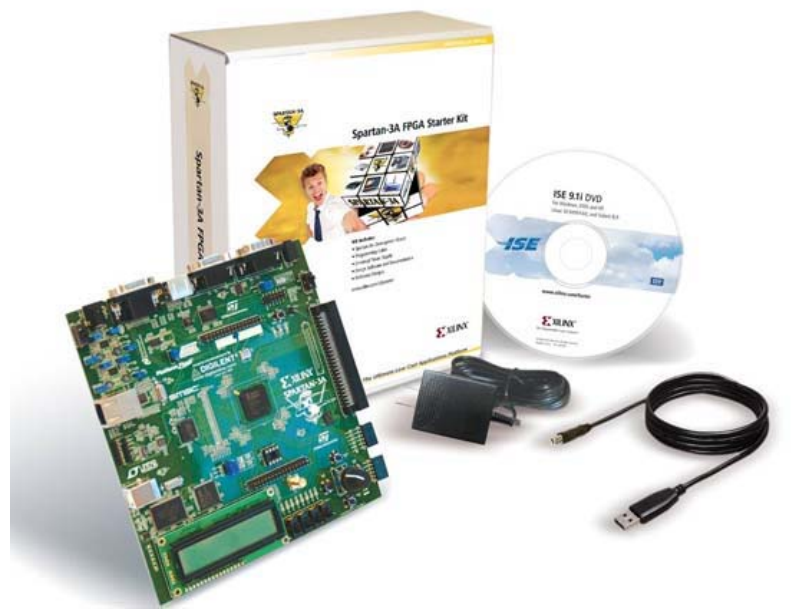

Figure 27. Spartan-3A, Xilinx company.

\section{References}

[1] S. Raghavan, "Digital Control for Speed and Position of a DC Motor," MS Thesis, Texas A \& M University Kingsville, 2005.

[2] Z. Xiu, and G. Ren, "Optimization Design of TS-PID Fuzzy Controllers Based on Genetic Algorithms," 5th World Congress on Intelligent Control and Automation, Hangzhou, 2004, pp. 2476-2480.

[3] S. Z. He, S. Tan and F. L. Xu, "Fuzzy Self-Tuning of PID controllers," Fuzzy Sets and Systems, Vol. 56, No. 1, 1993, pp. 37-46. doi: 10.1016/0165-0114(93)90183-I

[4] B. Lacevic, J. Velagic and N. Osmic, (2007). "Design of Fuzzy Logic Based Mobile Robot Position Controller Using Genetic Algorithm," IEEE/ASME International Conference on Advanced Intelligent Mechatronics, Zurich, 2007, pp. 1-6.

[5] Xilinx Company, "Programmable Logic Design," 2006. http://www.xilinx.com/company/about/programmable

[6] Xilinx Company, "Spartan-3A Starter Kit Board User Guide," 2007. http://www.xilinx.com/bvdocs/userguides/ug330

[7] L. A. Zadeh, "Fuzzy Sets," Information and Control, Vol. 8, No. 3, 1965, pp. 338-353. doi:10.1016/S0019-9958(65)90241-X

[8] E. H. Mamdani, “Application of Fuzzy Algorithms for Control of Simple Dynamic Plant," Proceedings of the IEEE, Vol. 121, No. 12, 1974, pp. 1585-1588.

[9] L.-X. Wang, "A Course in Fuzzy Systems and Control," Prentice-Hall, Inc., Upper Saddle River, 1997.

[10] M.-Y. Shieh and T.-H. S. Li, "Design and Implementation of Integrated Fuzzy Logic Controller for Servo-Motor System," Mechatronics, Vol. 8, No. 3, 1998, pp. 217-240. doi:10.1016/S0957-4158(97)00052-4

[11] J. Birkner et al., "A Very-High-Speed Field-Programmable Gate Array Using Metal-to-Metal Antifuse Programmable Elements," Microelectronics Journal, Vol. 23, No. 7, 1992, pp. 561-568. doi:10.1016/0026-2692(92)90067-B

[12] S. Poorani, T. V. S. Urmila Priya, K. Udaya Kumar and S. Renganarayanan, "FPGA Based Fuzzy Logic Controller for Electric Vehicle," Journal of the Institution of Engineers, Vol. 45 No. 5, 2005, pp. 1-14.

[13] T. Runghimmawan, S. Intajag and V. Krongratana, "Fuzzy Logic PID Controller Based on FPGA for Process Control," IEEE International Symposium on Industrial Electronics, Vol. 2, No. 11, 2004, pp. 1495-1500.

[14] D. Zhang, et al., "Digital Anti-Windup PI Controllers for Variable-Speed Motor Drives Using FPGA and Stochastic Theory," IEEE Transactions on Power Electronics, Vol. 21, No. 5, 2006, pp. 1496-1501. doi:10.1109/TPEL.2006.882342 